\title{
The High-Temperature Synthesis of the Nanoscaled White-Light Phosphors Applied in the White-Light LEDs
}

\author{
Hao-Ying Lu and Meng-Han Tsai \\ Department of Electronic Engineering, National Quemoy University, Kinmen 89250, Taiwan \\ Correspondence should be addressed to Hao-Ying Lu; hylu@nqu.edu.tw
}

Received 1 August 2014; Accepted 19 August 2014

Academic Editor: Luigi Nicolais

Copyright ( $) 2015$ H.-Y. Lu and M.-H. Tsai. This is an open access article distributed under the Creative Commons Attribution License, which permits unrestricted use, distribution, and reproduction in any medium, provided the original work is properly cited.

\begin{abstract}
The white-light phosphors consisting of $\mathrm{Dy}^{3+}$ doped $\mathrm{YPO}_{4}$ and $\mathrm{Dy}^{3+}$ doped $\mathrm{YP}_{1-X} \mathrm{~V}_{X} \mathrm{O}_{4}$ were prepared by the chemical coprecipitation method. After the $1200^{\circ} \mathrm{C}$ thermal treatment in the air atmosphere, the white-light phosphors with particle sizes around $90 \mathrm{~nm}$ can be obtained. In order to reduce the average particle size of phosphors, the alkaline washing method was applied to the original synthesis process, which reduces the particle sizes to $65 \mathrm{~nm}$. From the PLE spectra, four absorption peaks locating at $325,352,366$, and $390 \mathrm{~nm}$ can be observed in the $\mathrm{YPO}_{4}$-based phosphors. These peaks appear due to the following electron transitions: ${ }^{6} \mathrm{H}_{15 / 2} \rightarrow{ }^{4} \mathrm{~K}_{15 / 2},{ }^{6} \mathrm{H}_{15 / 2} \rightarrow{ }^{4} \mathrm{M}_{15 / 2}+{ }^{6} \mathrm{P}_{7 / 2},{ }^{6} \mathrm{H}_{15 / 2} \rightarrow{ }^{4} \mathrm{I}_{11 / 2}$, and ${ }^{6} \mathrm{H}_{15 / 2} \rightarrow{ }^{4} \mathrm{M}_{19 / 2}$. Besides, the emission peaks of wavelengths $484 \mathrm{~nm}$ and $576 \mathrm{~nm}$ can be observed in the PL spectra. In order to obtain the white-light phosphors, the vanadium ions were applied to substitute the phosphorus ions to compose the $\mathrm{YP}_{1-X} \mathrm{~V}_{X} \mathrm{O}_{4}$ phosphors. From the PL spectra, the strongest PL intensity can be obtained with $30 \%$ vanadium ions. As the concentration of vanadium ions increases to $40 \%$, the phosphors with the CIE coordinates locating at the white-light area can be obtained.
\end{abstract}

\section{Introduction}

Due to the excellent luminescent properties and chemical stabilities, the phosphors using yttrium vanadate $\left(\mathrm{YVO}_{4}\right)$ and yttrium phosphate $\left(\mathrm{YPO}_{4}\right)$ as the host materials have been used in a broad range of daily life, such as the cathode ray tubes, electroluminescence devices, field emission displays, plasma display panels, projection displays, and ultraviolet light-emitting diodes (UV-LEDs) [1-4]. The europium $\left(\mathrm{Eu}^{3+}\right)$ doped $\mathrm{YVO}_{4}$ phosphor especially is one of the excellent commercial red-light phosphors, which has been studied for many years [5-9]. In addition to the $\mathrm{Eu}^{3+}$ ions, the phosphor doped with dysprosium $\left(\mathrm{Dy}^{3+}\right)$ ions is also a potential luminescent material. The active center $\mathrm{Dy}^{3+}$ can yield two emission bands: the yellow-light band and the bluelight band, and these two emission bands originate from the transition ${ }^{4} \mathrm{~F}_{9 / 2} \rightarrow{ }^{6} \mathrm{H}_{15 / 2}$ and the transition ${ }^{4} \mathrm{~F}_{9 / 2} \rightarrow$ ${ }^{6} \mathrm{H}_{13 / 2}$, respectively.

Through adjusting the relative intensities of yellowlight band and blue-light band, it is possible to obtain the white-light phosphors [8,10-12]. Owing to the same crystal structure, similar lattice constants, and similar physical and chemical properties between $\mathrm{YPO}_{4}$ and $\mathrm{YVO}_{4}$ phosphors, the material $\mathrm{Y}(\mathrm{P}, \mathrm{V}) \mathrm{O}_{4}$ has been paid much attention to in recent decades [13-15].

In accordance with the above advantages, different synthesis methods were applied to produce the $\mathrm{Y}(\mathrm{P}, \mathrm{V}) \mathrm{O}_{4}$ phosphors in recent years. Bao et al. synthesized the phosphors via the sol-gel method in 2008; the average particle size is around $80 \mathrm{~nm}$ with the $1000^{\circ} \mathrm{C}$ thermal treatment [16]. In 2009, Nguyen et al. applied the hydrothermal method to produce the $\mathrm{Y}(\mathrm{P}, \mathrm{V}) \mathrm{O}_{4}$ phosphors, under the $1000^{\circ} \mathrm{C}$ synthesis temperature; the particle sizes are around 70 to $90 \mathrm{~nm}$ [17]. Additionally, the solid-state method is also a common method to synthesize the phosphors. Under the $1200^{\circ} \mathrm{C}$ thermal treatment for 6 hours, the phosphors with particle sizes around 2 to $4 \mu \mathrm{m}$ can be obtained [18]. The methods above are either complicated or larger particle sizes. In this research, the chemical coprecipitation method with thermal treatments is adopted to synthesize the phosphors. In 2005, Su and Yanever used the similar processes to synthesize 
the $\mathrm{Y}(\mathrm{P}, \mathrm{V}) \mathrm{O}_{4}$ phosphors at $1100^{\circ} \mathrm{C}$, but the average particle sizes are around 0.5 to $2 \mu \mathrm{m}$ [19]. In order to reduce the particle sizes, the alkaline-washing method was applied to the chemical coprecipitation method in this research and it can reduce the average particle size to $65 \mathrm{~nm}$ effectively.

\section{Materials and Methods}

In this study, yttrium nitrate hexahydrate $\mathrm{Y}\left(\mathrm{NO}_{3}\right)_{3} \cdot 6 \mathrm{H}_{2} \mathrm{O}$ (99.9\%, Alfa Aesar), dysprosium nitrate pentahydrate $\mathrm{Dy}\left(\mathrm{NO}_{3}\right)_{3} \cdot 5 \mathrm{H}_{2} \mathrm{O}$ (99.9\%, Alfa Aesar), phosphoric acid $\mathrm{H}_{3} \mathrm{PO}_{4}\left(85 \%\right.$, Panreac), and ammonium vanadate $\mathrm{NH}_{4} \mathrm{VO}_{3}$ (99.5\%, Acros Organics) were used as the starting materials. At first, $\mathrm{Y}\left(\mathrm{NO}_{3}\right)_{3} \cdot 6 \mathrm{H}_{2} \mathrm{O}, \mathrm{Dy}\left(\mathrm{NO}_{3}\right)_{3} \cdot 5 \mathrm{H}_{2} \mathrm{O}$ and $\mathrm{H}_{3} \mathrm{PO}_{4}$ were dissolved into distilled water by the stoichiometric ratio and the mixed solution was stirred for an hour at room temperature. Secondly, ammonia was used as the precipitant and added into the above solution. With the addition of ammonia, the $\mathrm{pH}$ value of mixed solution was adjusted to 8.0, and this solution was placed for 12 hours. After 12 hours, the white precipitation could be observed and separated directly by a centrifuge. Thirdly, the precipitation was washed by distilled water and ethanol for several times. Finally, the dried precipitation was used as the precursor to synthesize the $\mathrm{YPO}_{4}: \mathrm{Dy}^{3+}$ and $\mathrm{YP}_{1-\mathrm{X}} \mathrm{V}_{X} \mathrm{O}_{4}: \mathrm{Dy}^{3+}$ phosphors by the suitable thermal treatment in the air atmosphere for 1 hour.

Alkaline washing process: the precipitation was washed with ammonia and dried directly. Then, the dried powders can be used as the precursor.

The X-ray diffraction patterns of phosphors were collected by Rigaku Miniflex II desktop X-ray diffractometer with $\mathrm{Cu}-\mathrm{K} \alpha$ radiation. The particle morphology was studied by a field emission scanning electron microscope (FESEM, JEOL JSM-6500F). And the optical properties were studied with a fluorescence spectrophotometer (Hitachi F-2700PL).

\section{Results and Discussion}

Figure 1 shows the XRD patterns of $\mathrm{YPO}_{4}$ phosphors with different thermal treatments. It can be seen from this figure that the three predominant peaks locating at $2 \theta=25.9^{\circ}$, $35.0^{\circ}$, and $51.8^{\circ}$ appear due to the following diffraction planes: (200), (112), and (312) of $\mathrm{YPO}_{4}$. Comparing with the JCPDS standard card (number 11-0254), the crystalline structures of all $\mathrm{YPO}_{4}$ phosphors prepared through the chemical coprecipitation method are confirmed as the tetragonal structures. No impurity phases resulting from the starting materials can be observed. As the thermal treatment temperature increases, the better crystallinity can be obtained.

The scanning electron microscope (SEM) images are shown in Figure 2. The irregular shape and agglomeration phenomenon of nanoparticles can be observed. The average particle size of phosphors is about $90 \mathrm{~nm}$ with the $1200^{\circ} \mathrm{C}$ thermal treatment and the agglomeration of phosphors is serious. From Figure 2(b), the particle size of phosphors reduces to $65 \mathrm{~nm}$ with the alkaline washing process and this process can also improve the agglomeration of phosphors.

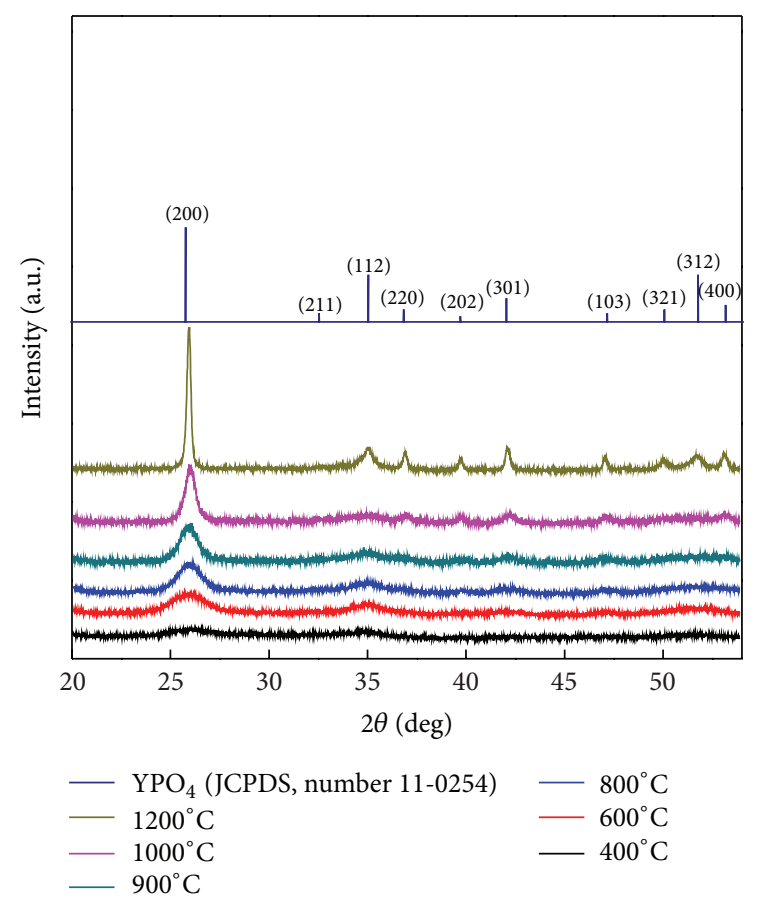

FIGURE 1: The XRD patterns of $\mathrm{YPO}_{4}$ phosphors with different thermal treatments.

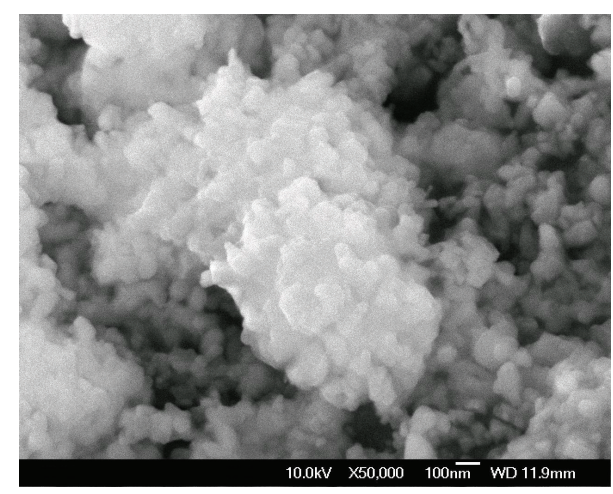

(a)

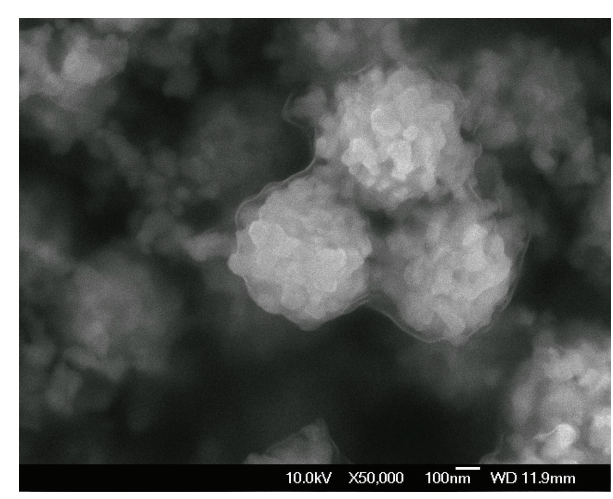

(b)

Figure 2: The SEM images of $\mathrm{YPO}_{4}$ phosphors with the $1200^{\circ} \mathrm{C}$ thermal treatment. (a) $1200^{\circ} \mathrm{C}$. (b) $1200^{\circ} \mathrm{C}$ with the alkaline-washing process. 


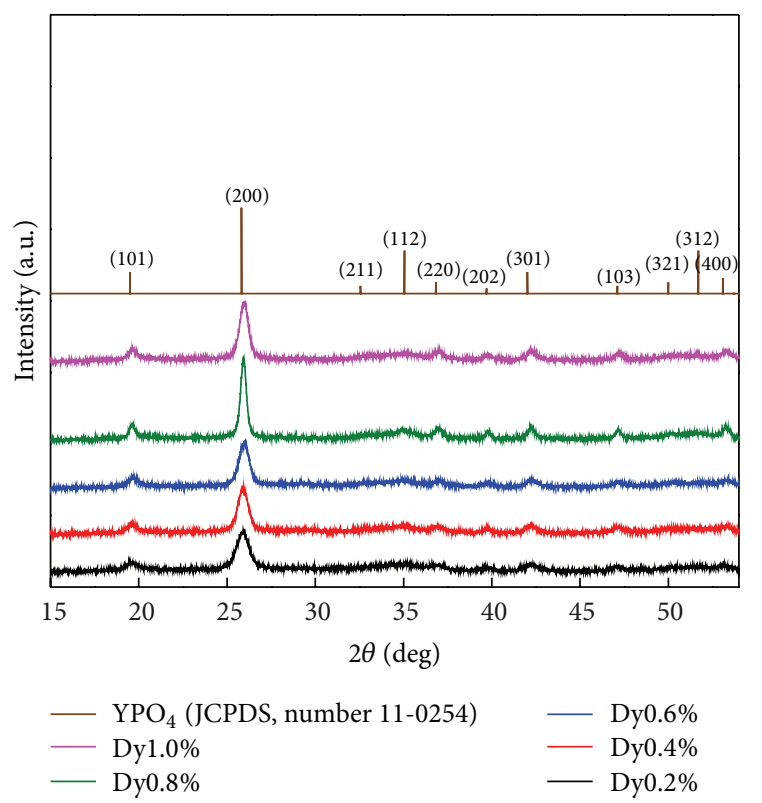

FIGURE 3: The XRD patterns of $\mathrm{YPO}_{4}$ phosphors with different dopant concentrations.

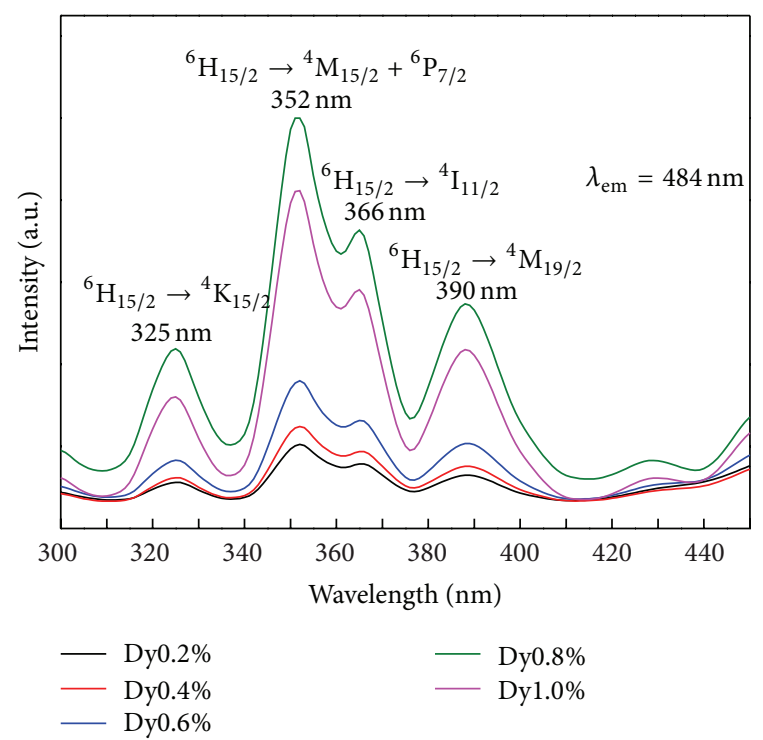

FIgURE 4: The PLE spectra of $\mathrm{YPO}_{4}: \mathrm{Dy}^{3+}$ phosphors with different dopant concentrations, $\lambda_{\mathrm{em}}=484 \mathrm{~nm}$.

Figure 3 shows the XRD patterns of $\mathrm{YPO}_{4}$ phosphors with different dopant concentrations. In this figure, the lattice constants of phosphors change with the dopant concentrations, but all XRD patterns still exhibit the tetragonal structure. Small enlargement in the lattice constants of the $\mathrm{YPO}_{4}: \mathrm{Dy}^{3+}$ from $\mathrm{YPO}_{4}$ occurs due to the presence of $\mathrm{Dy}^{3+}$ (ionic radii of $\mathrm{Dy}^{3+}$ and $\mathrm{Y}^{3+}$ are $0.912 \AA$ and $0.900 \AA$, resp.). The PLE spectra of $\mathrm{YPO}_{4}: \mathrm{Dy}^{3+}$ phosphors are revealed in Figure 4 with the emission wavelength $\left(\lambda_{\mathrm{em}}\right) 484 \mathrm{~nm}$. Four absorption peaks can be observed from the PLE spectra. The $325 \mathrm{~nm}$ absorption peak originates from the $\mathrm{f}-\mathrm{f}$ transition ${ }^{6} \mathrm{H}_{15 / 2} \rightarrow{ }^{4} \mathrm{~K}_{15 / 2}$

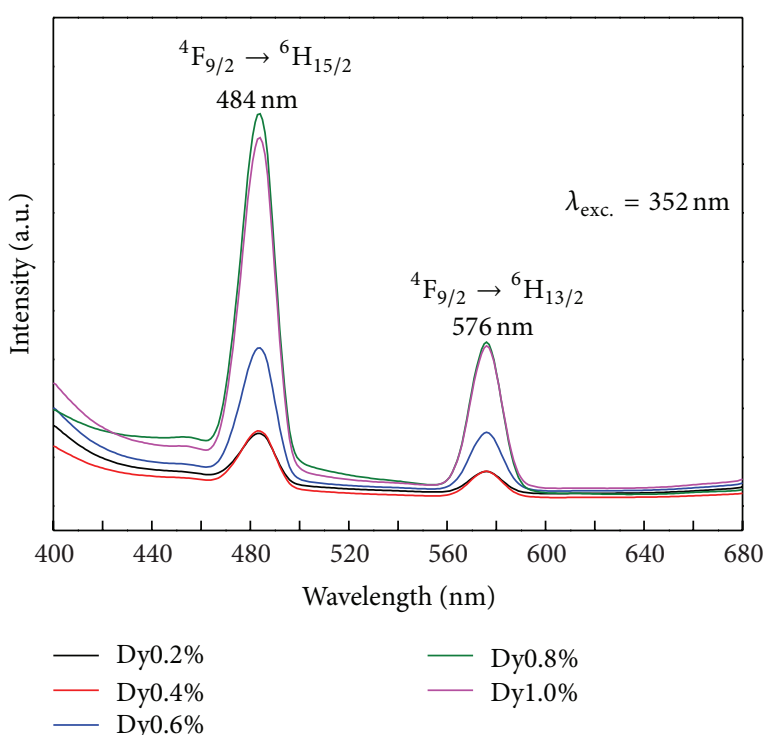

FIgURE 5: The PL spectra of $\mathrm{YPO}_{4}: \mathrm{Dy}^{3+}$ phosphors with different dopant concentrations, $\lambda_{\text {exc }}=352 \mathrm{~nm}$.

within $\mathrm{Dy}^{3+}$. And the $352 \mathrm{~nm}, 366 \mathrm{~nm}$, and $390 \mathrm{~nm}$ absorption peaks appear because of the following transitions: ${ }^{6} \mathrm{H}_{15 / 2} \rightarrow{ }^{4} \mathrm{M}_{15 / 2}+{ }^{4} \mathrm{P}_{7 / 2},{ }^{6} \mathrm{H}_{15 / 2} \rightarrow{ }^{4} \mathrm{I}_{11 / 2}$, and ${ }^{6} \mathrm{H}_{15 / 2} \rightarrow$ ${ }^{4} \mathrm{M}_{19 / 2}$, respectively. Herein, the $352 \mathrm{~nm}$ peak is the strongest absorption peak of all peaks and is chosen as the excitation wavelength in the following PL measurements.

Figure 5 demonstrates the PL spectra of $\mathrm{YPO}_{4}: \mathrm{Dy}^{3+}$ phosphors. Two emission peaks can be observed from the $\mathrm{PL}$ spectra. The $484 \mathrm{~nm}$ peak is the result from the transition ${ }^{4} \mathrm{~F}_{9 / 2} \rightarrow{ }^{6} \mathrm{H}_{15 / 2}$ and the $576 \mathrm{~nm}$ peak occurs as the result of the transition ${ }^{4} \mathrm{~F}_{9 / 2} \rightarrow{ }^{6} \mathrm{H}_{13 / 2}$. The PL intensity increases with the $\mathrm{Dy}^{3+}$ ion concentration. As the $\mathrm{Dy}^{3+}$ ion concentration increases to $0.8 \%$, the phosphor can possess the strongest luminescent property. When the dopant concentration is above $0.8 \%$, the concentration quench effect can be observed obviously.

Figure 6 shows the XRD patterns of $\mathrm{Y}_{0.992} \mathrm{P}_{1-X} \mathrm{~V}_{X} \mathrm{O}_{4}: 0.008 \mathrm{Dy}^{3+}$ phosphors. The $X$ means vanadium ion concentration and it starts from 0.1 to 0.5 . As mentioned in [18], the cell parameters of $\mathrm{YPO}_{4}$ are $a=$ $b=6.8817 \AA ; c=6.0177 \AA$ and those of $\mathrm{YVO}_{4}$ are $a=b=$ $7.1183 \AA ; c=6.2893 \AA$. When the concentration of vanadium ions increases, the angles of all diffraction peaks tend to be smaller (ionic radii of $\mathrm{P}^{5+}$ and $\mathrm{V}^{5+}$ are $0.34 \AA$ and $0.59 \AA$, resp.). The lattice constant of $\mathrm{Y}_{0.992} \mathrm{P}_{1-X} \mathrm{~V}_{X} \mathrm{O}_{4}: 0.008 \mathrm{Dy}^{3+}$ phosphor increases close to the lattice constant of $\mathrm{YVO}_{4}$ with vanadium quantity. Three predominant peaks locating at $25.4^{\circ}, 34.2^{\circ}$, and $50.6^{\circ}$ result from the diffraction planes (200), (112), and (312). The almost similar XRD patterns indicate that the presence of $\mathrm{V}^{5+}$ does not affect the crystal structure of the $\mathrm{Y}(\mathrm{P}, \mathrm{V}) \mathrm{O}_{4}$ phosphors.

The PLE spectra of $\mathrm{Y}_{0.992} \mathrm{P}_{1-X} \mathrm{~V}_{X} \mathrm{O}_{4}: 0.008 \mathrm{Dy}^{3+}$ phosphors are shown in Figure 7. With the emission wavelength $484 \mathrm{~nm}, 3$ absorption peaks locating at 352, 366, and $390 \mathrm{~nm}$ 


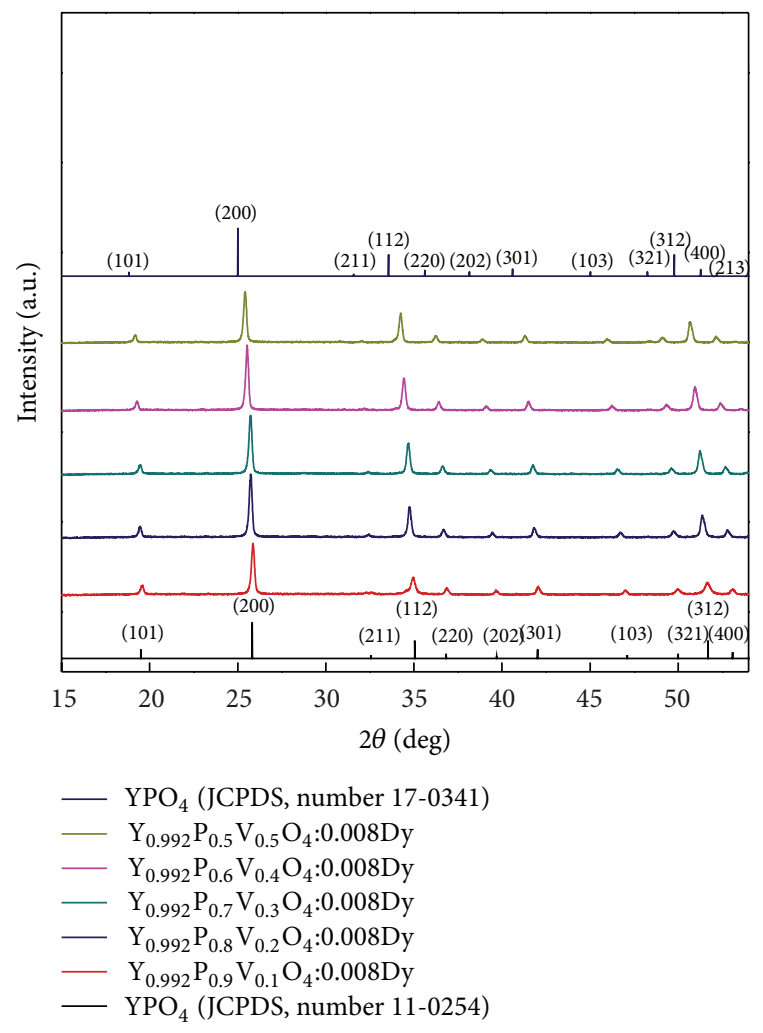

FIgURE 6: The XRD patterns of $\mathrm{Y}_{0.992} \mathrm{P}_{1-X} \mathrm{~V}_{X} \mathrm{O}_{4}: 0.008 \mathrm{Dy}^{3+}$ phosphors $(X=1$ to 0.5$)$.

can be observed. These peaks are the results of the following electron transitions: ${ }^{6} \mathrm{H}_{15 / 2} \rightarrow{ }^{4} \mathrm{M}_{15 / 2}+{ }^{6} \mathrm{P}_{7 / 2},{ }^{6} \mathrm{H}_{15 / 2} \rightarrow$ ${ }^{4} \mathrm{I}_{11 / 2}$ and ${ }^{6} \mathrm{H}_{15 / 2} \rightarrow{ }^{4} \mathrm{M}_{19 / 2}$, respectively. The $352 \mathrm{~nm}$ absorption peak is still the strongest absorption peak of all and is chosen as the excitation wavelength for the PL measurements. Figure 8 shows the PL spectra of $\mathrm{Y}_{0.992} \mathrm{P}_{1-X} \mathrm{~V}_{X} \mathrm{O}_{4}: 0.008 \mathrm{Dy}^{3+}$ phosphors. These two emission peaks locating at $484 \mathrm{~nm}$ and $576 \mathrm{~nm}$ can be observed in the PL spectra. These two peaks originate from the electron transitions ${ }^{4} \mathrm{~F}_{9 / 2} \rightarrow{ }^{6} \mathrm{H}_{15 / 2}$ and ${ }^{4} \mathrm{~F}_{9 / 2} \rightarrow{ }^{6} \mathrm{H}_{13 / 2}$, respectively. As the concentration of vanadium ions increases, the PL intensity increases. When the vanadium concentration reaches $30 \%$, the phosphor can possess the best emission property. According to the CIE coordinates in Figure 9, the phosphor $\mathrm{Y}_{0.992} \mathrm{PO}_{4}: 0.008 \mathrm{Dy}{ }^{3+}$ can be used as a blue-white phosphor. With the addition of vanadium ions, the CIE coordinates can be adjusted to the white-light area. From Figure 9(b), the coordinates of phosphors with $40 \%$ and $50 \%$ vanadium concentration locate at $(0.269,0.317)$ and $(0.279,0.327)$.

\section{Conclusion}

The white-light phosphors with average particle size $90 \mathrm{~nm}$ can be obtained through the chemical coprecipitation method with suitable thermal treatments in this study. The alkaline-washing process was applied to the original synthesis

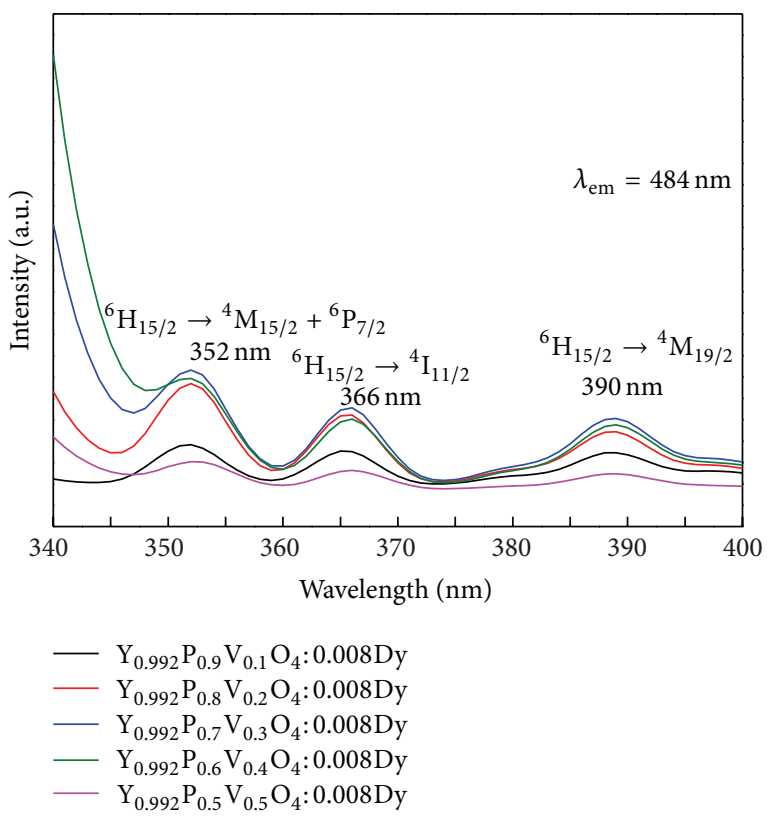

Figure 7: The PLE spectra of $\mathrm{Y}_{0.992} \mathrm{P}_{1-\mathrm{X}} \mathrm{V}_{X} \mathrm{O}_{4}: 0.008 \mathrm{Dy}{ }^{3+}$ phosphors ( $X=1$ to 0.5$), \lambda_{\text {em }}=484 \mathrm{~nm}$.

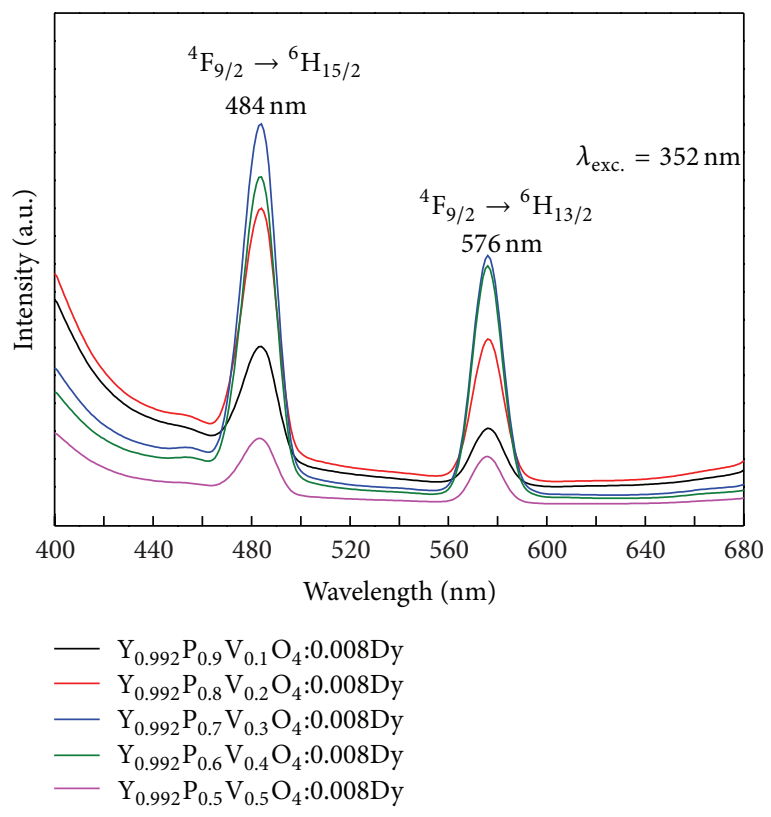

Figure 8: The PL spectra of $\mathrm{Y}_{0.992} \mathrm{P}_{1-X} \mathrm{~V}_{X} \mathrm{O}_{4}: 0.008 \mathrm{Dy}^{3+}$ phosphors $(X=1$ to 0.5$), \lambda_{\text {exc }}=352 \mathrm{~nm}$.

to reduce the average particle size. In this research, the particle size of phosphors can be reduced to $65 \mathrm{~nm}$ through the alkaline washing process and this process can also improve the agglomeration phenomenon. From the XRD patterns, the $\mathrm{YPO}_{4}$ phosphors with different thermal treatments all crystallize into the tetragonal structure. The lattice constant increases with the concentration of vanadium ions and tends to the lattice constant of $\mathrm{YVO}_{4}$. There are four absorption peaks observed in the PLE spectra, which are the results 


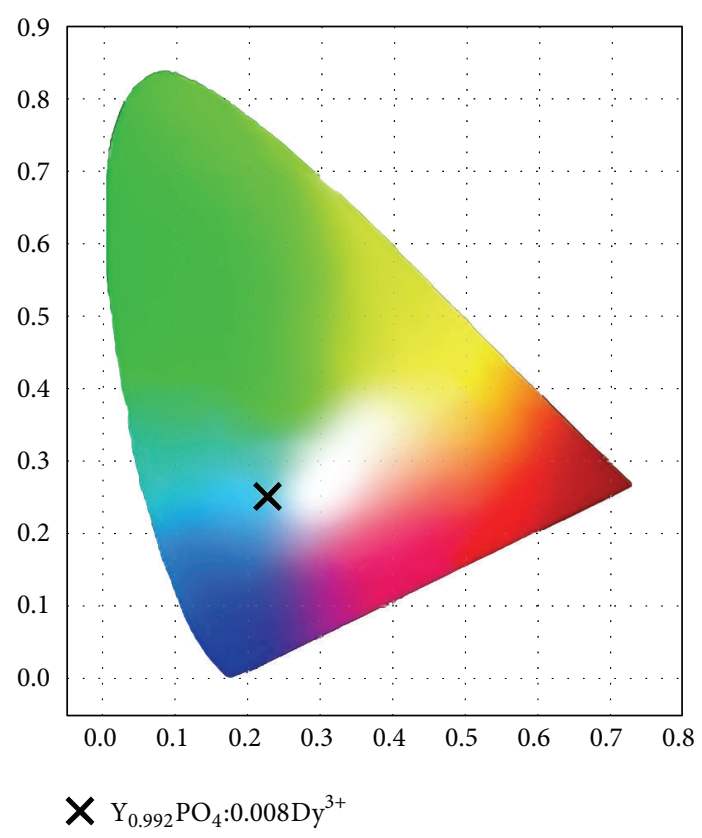

(a)

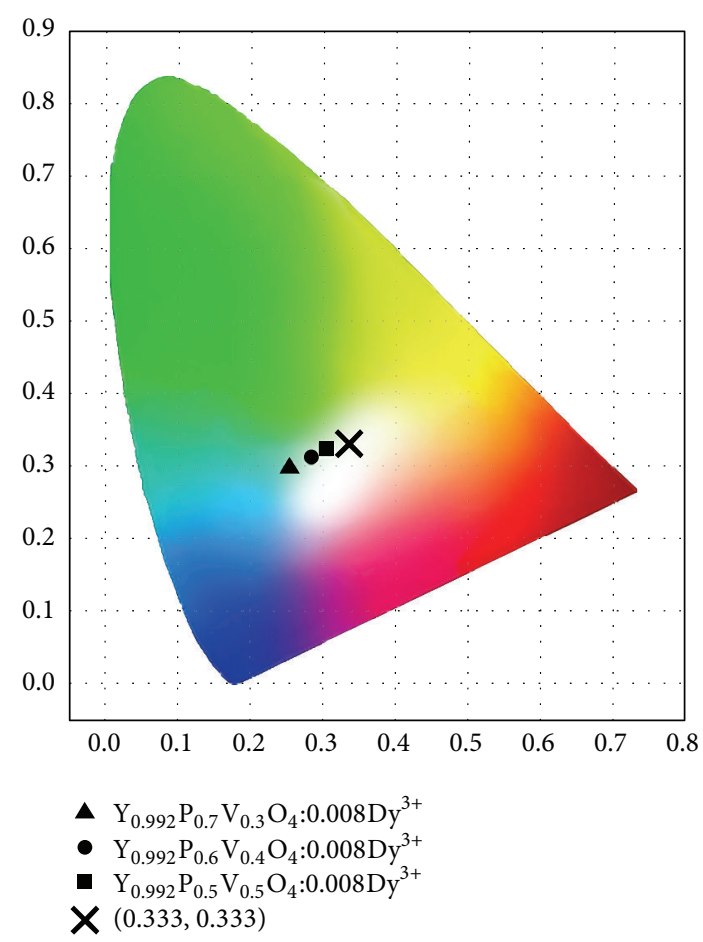

(b)

FIGURE 9: The CIE coordinates of (a) $\mathrm{YPO}_{4}: \mathrm{Dy}^{3+}$ phosphor and (b) $\mathrm{Y}(\mathrm{P}, \mathrm{V}) \mathrm{O}_{4}: \mathrm{Dy}^{3+}$ phosphors.

of the transitions ${ }^{6} \mathrm{H}_{15 / 2} \rightarrow{ }^{4} \mathrm{~K}_{15 / 2},{ }^{6} \mathrm{H}_{15 / 2} \rightarrow{ }^{4} \mathrm{M}_{15 / 2}+$ ${ }^{4} \mathrm{P}_{7 / 2},{ }^{6} \mathrm{H}_{15 / 2} \rightarrow{ }^{4} \mathrm{I}_{11 / 2}$, and ${ }^{6} \mathrm{H}_{15 / 2} \rightarrow{ }^{4} \mathrm{M}_{19 / 2}$. Additionally, two emission peaks locating at $484 \mathrm{~nm}$ and $576 \mathrm{~nm}$ can be observed in the PL spectra and they originate from the electron transitions, ${ }^{4} \mathrm{~F}_{9 / 2} \rightarrow{ }^{6} \mathrm{H}_{15 / 2}$ and ${ }^{4} \mathrm{~F}_{9 / 2} \rightarrow$ ${ }^{6} \mathrm{H}_{13 / 2}$, respectively. By substituting the vanadium ions for the phosphorus ions in $\mathrm{YPO}_{4}$ phosphors, the relative intensities of these two emission peaks can be tuned to produce the white-light phosphor. The $40 \%$ vanadium concentration is the optimal condition to obtain the white-light phosphor $\mathrm{Y}_{0.992} \mathrm{P}_{0.6} \mathrm{~V}_{0.4} \mathrm{O}_{4}: 0.008 \mathrm{Dy}^{3+}$ in our work. It is believed that the chemical coprecipitation method with thermal treatments is an effective way to obtain the white-light phosphors.

\section{Conflict of Interests}

The authors declare that there is no conflict of interests regarding the publication of this paper.

\section{References}

[1] L. Chen, G. Liu, Y. Liu, and K. Huang, "Synthesis and luminescence properties of $\mathrm{YVO}_{4}: \mathrm{Dy}^{3+}$ nanorods," Journal of Materials Processing Technology, vol. 198, no. 1-3, pp. 129-133, 2008.

[2] L. R. Singh, R. S. Ningthoujam, N. S. Singh, and S. D. Singh, "Probing $\mathrm{Dy}^{3+}$ ions on the surface of nanocrystalline $\mathrm{YVO}_{4}$ : luminescence study," Optical Materials, vol. 32, no. 2, pp. 286292, 2009.

[3] J. Huang, Q. Li, and D. Chen, "Luminescent properties of $\mathrm{Eu}^{3+}$ activated nanophosphors $\mathrm{Ca}_{3} \mathrm{Y}_{0.8} \mathrm{Gd}_{0.2}\left(\mathrm{VO}_{4}\right)_{2.4}\left(\mathrm{PO}_{4}\right)_{0.6}: \mathrm{Eu}^{3+}$ for light-emitting diodes," Materials Letters, vol. 64, no. 21, pp. 2334-2336, 2010.

[4] Y. Y. He, M. Q. Zhao, Y. Y. Song, and G. Y. Zhao, "Effects of excitation wavelength and $\mathrm{Y}^{3+}$ content on luminescent properties of $\mathrm{YMO}_{4}: \mathrm{Dy}^{3+}(\mathrm{M}=\mathrm{V}, \mathrm{P})$ phosphors induced by ultraviolet excitation," Materials Research Bulletin, vol. 47, no. 7, pp. 1821-1826, 2012.

[5] C. Brecher, H. Samelson, A. Lempicki, R. Riley, and T. Peters, "Polarized spectra and crystal-field parameters of $\mathrm{Eu}^{3+}$ in $\mathrm{YVO}_{4}$," Physical Review, vol. 155, no. 2, pp. 2334-2336, 1967.

[6] S. Osawa, T. Katsumata, T. Iyoda, Y. Enoki, S. Komuro, and T. Morikawa, "Effects of composition on the optical properties of doped and nondoped $\mathrm{GdVO}_{4}$ ", Journal of Crystal Growth, vol. 198-199, pp. 444-448, 1999.

[7] H.-D. Jiang, H.-J. Zhang, J.-Y. Wang et al., "Optical and laser properties of Nd:GdVO 4 crystal," Optics Communications, vol. 198, no. 4-6, pp. 447-452, 2001.

[8] E. Cavalli, M. Bettinelli, A. Belletti, and A. Speghini, "Optical spectra of yttrium phosphate and yttrium vanadate single crystals activated with Dy ${ }^{3+}$," Journal of Alloys and Compounds, vol. 341, no. 1-2, pp. 107-110, 2002.

[9] B. Yan and X.-Q. Su, "LuVO $: \mathrm{RE}^{3+}(\mathrm{RE}=\mathrm{Sm}, \mathrm{Eu}, \mathrm{Dy}, \mathrm{Er})$ phosphors by in-situ chemical precipitation construction of hybrid precursors," Optical Materials, vol. 29, no. 5, pp. 547-551, 2007.

[10] S. D. Han, S. P. Khatkar, V. B. Taxak, G. Sharma, and D. Kumar, "Synthesis, luminescence and effect of heat treatment on the properties of $\mathrm{Dy}^{3+}$-doped $\mathrm{YVO}_{4}$ phosphor," Materials Science and Engineering B, vol. 129, no. 1-3, pp. 126-130, 2006.

[11] Y. H. Zhou and J. Lin, "Luminescent properties of $\mathrm{YVO}_{4}: \mathrm{Dy}^{3+}$ phosphors prepared by spray pyrolysis," Journal of Alloys and Compounds, vol. 408-412, pp. 856-859, 2006.

[12] Z. Xiu, Z. Yang, M. Lü, S. Liu, H. Zhang, and G. Zhou, "Synthesis, structural and luminescence properties of $\mathrm{Dy}^{3+}$ doped $\mathrm{YPO}_{4}$ nanocrystals," Optical Materials, vol. 29, no. 4, pp. 431-434, 2006. 
[13] K. Riwotzki and M. Haase, "Colloidal $\mathrm{YVO}_{4}$ : Eu and $\mathrm{YP}_{0.95} \mathrm{~V}_{0.05} \mathrm{O}_{4}$ : Eu nanoparticles: luminescence and energy transfer processes," Journal of Physical Chemistry B, vol. 105, no. 51, pp. 12709-12713, 2001.

[14] K.-S. Sohn, I. W. Zeon, H. Chang, S. K. Lee, and H. D. Park, "Combinatorial search for new red phosphors of high efficiency at VUV excitation based on the $\mathrm{YRO}_{4}(\mathrm{R}=\mathrm{As}, \mathrm{Nb}, \mathrm{P}, \mathrm{V})$ system," Chemistry of Materials, vol. 14, no. 5, pp. 2140-2148, 2002.

[15] C.-C. Wu, K.-B. Chen, C.-S. Lee, T.-M. Chen, and B.-M. Cheng, "Synthesis and VUV photoluminescence characterization of $(\mathrm{Y}, \mathrm{Gd})(\mathrm{V}, \mathrm{P}) \mathrm{O}_{4}: \mathrm{Eu}^{3+}$ as a potential red-emitting PDP phosphor," Chemistry of Materials, vol. 19, no. 13, pp. 3278-3285, 2007.

[16] A. Bao, H. Yang, C. Tao, Y. Zhang, and L. Han, "Luminescent properties of nanoparticles $\mathrm{YP}_{X} \mathrm{~V}_{1-X} \mathrm{O}_{4}$ : Dy phosphors," Journal of Luminescence, vol. 128, no. 1, pp. 60-66, 2008.

[17] H.-D. Nguyen, S.-I. Mho, and I.-H. Yeo, "Preparation and characterization of nanosized $(\mathrm{Y}, \mathrm{Bi}) \mathrm{VO}_{4}: \mathrm{Eu}^{3+}$ and $\mathrm{Y}(\mathrm{V}, \mathrm{P}) \mathrm{O}_{4}: \mathrm{Eu}^{3+}$ red phosphors," Journal of Luminescence, vol. 129, no. 12, pp. 1754-1758, 2009.

[18] J. Sun, J. Xian, Z. Xia, and H. Du, "Synthesis, structure and luminescence properties of $\mathrm{Y}(\mathrm{V}, \mathrm{P}) \mathrm{O}_{4}: \mathrm{Eu}^{3+}, \mathrm{Bi}^{3+}$ phosphors," Journal of Luminescence, vol. 130, no. 10, pp. 1818-1824, 2010.

[19] X.-Q. Su and B. Yan, "The synthesis and luminescence of $\mathrm{YP}_{x} \mathrm{~V}_{1-x} \mathrm{O}_{4}: \mathrm{Dy}^{3+}$ microcrystalline phosphors by in situ coprecipitation composition of hybrid precursors," Materials Chemistry and Physics, vol. 93, no. 2-3, pp. 552-556, 2005. 

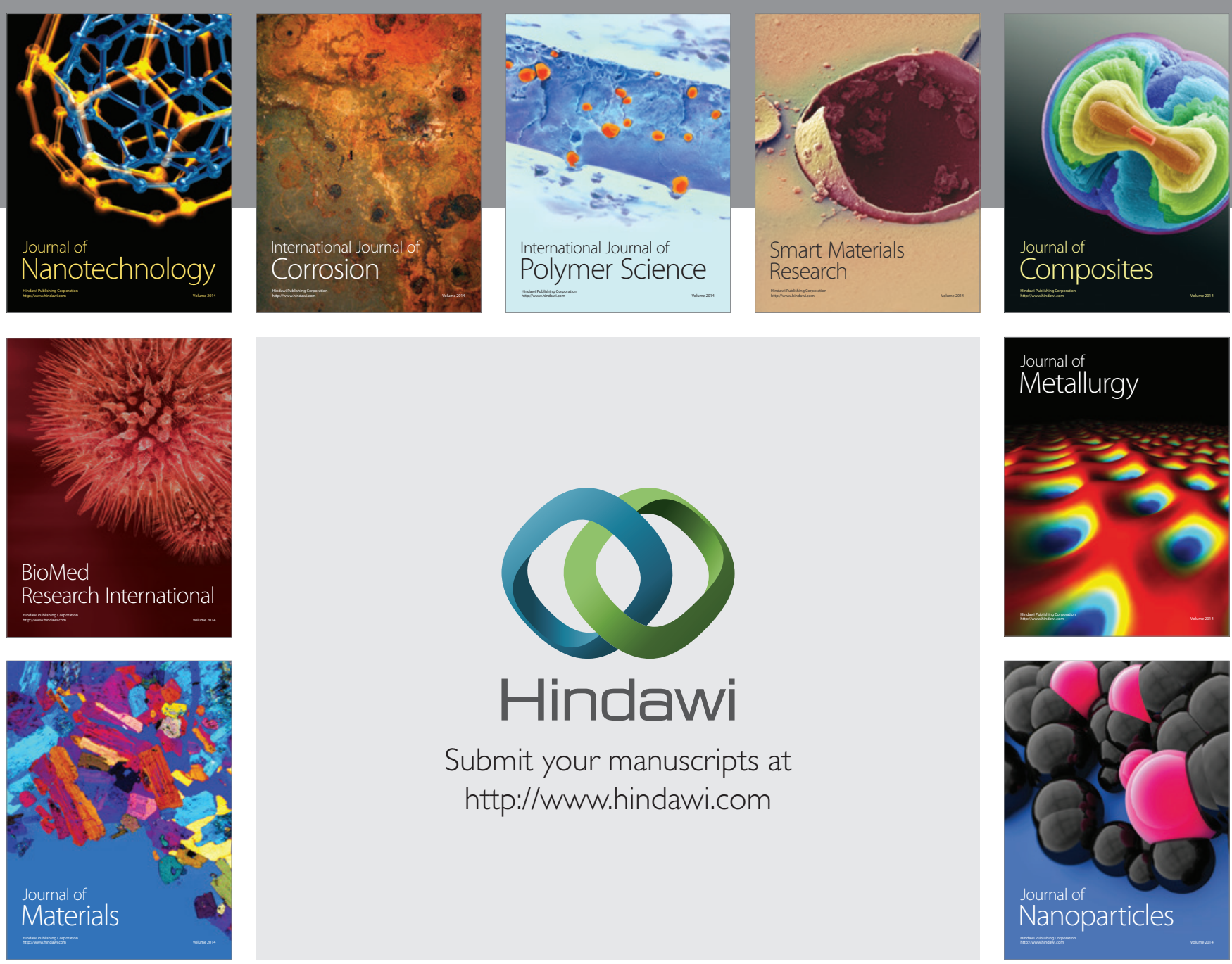

Submit your manuscripts at http://www.hindawi.com
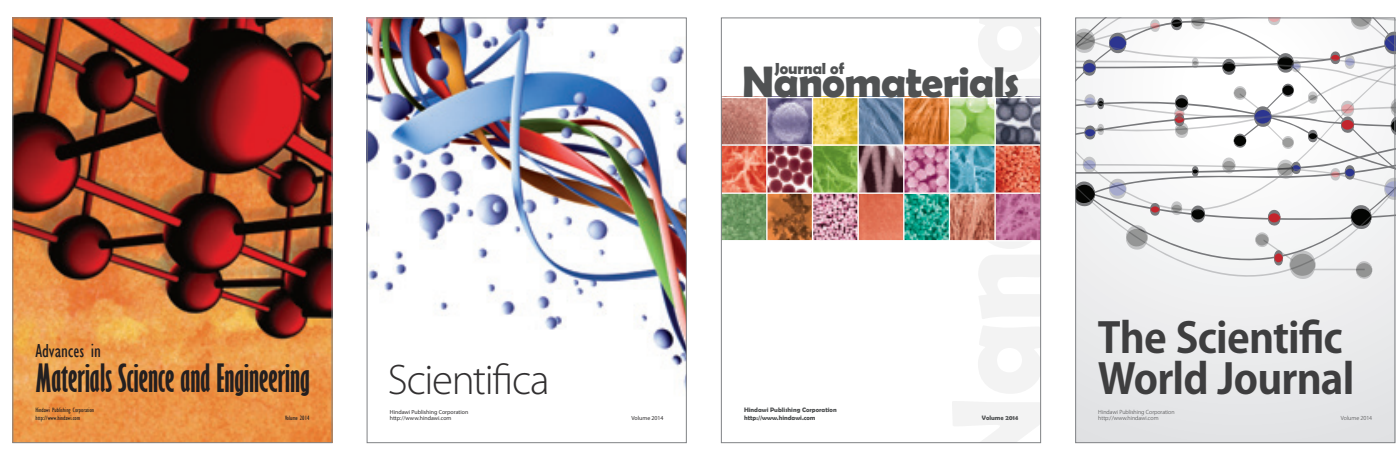

\section{The Scientific World Journal}
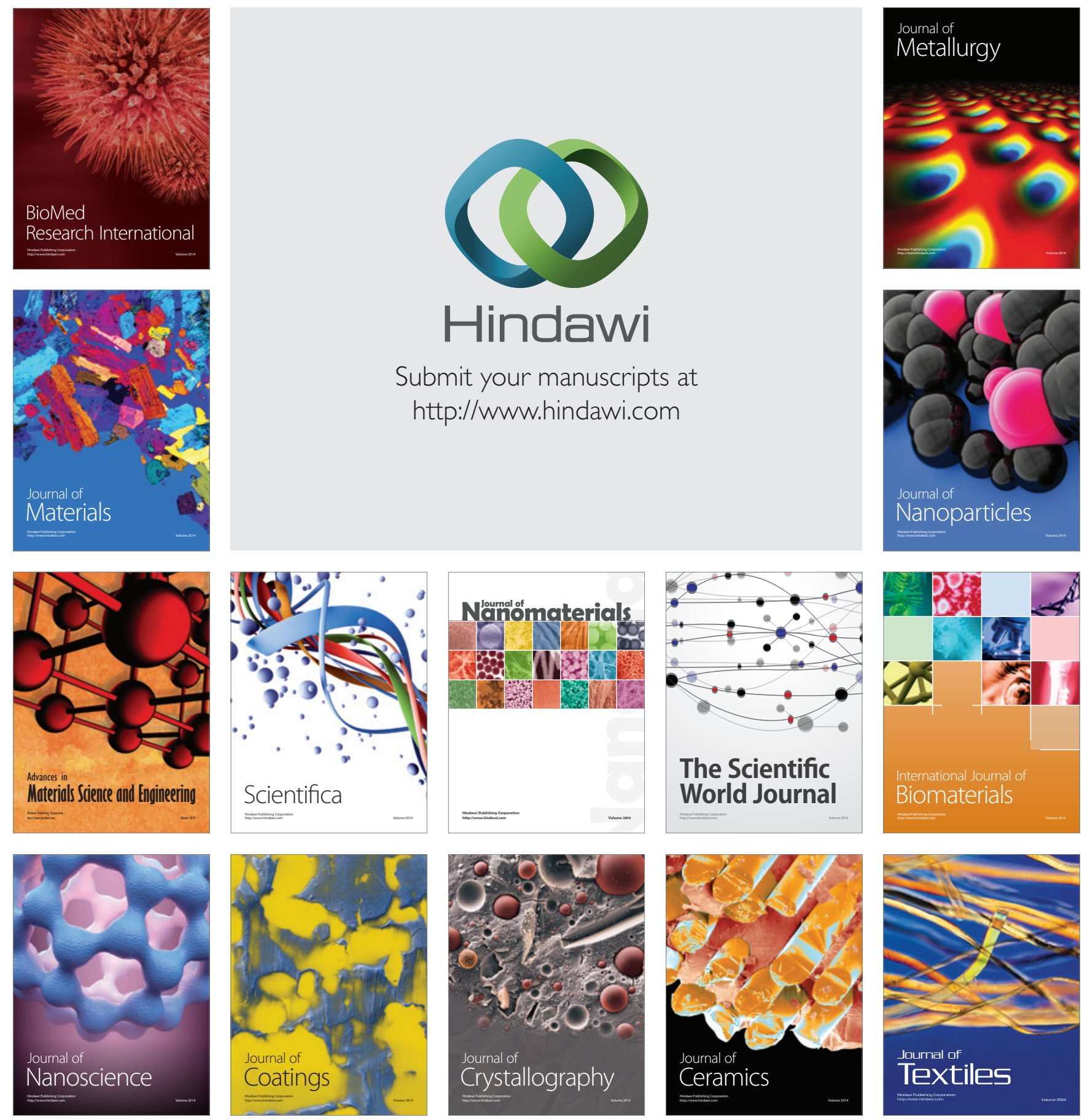